Citation: E. Zhllima, D. Imami, N. Bytyqi, M. Canavari, E. Merkaj, C. Chan (2020) Emerging Consumer Preference for Wine Attributes in a European Transition Country - the Case of Kosovo. Wine Economics and Policy 9(1): 63-72. doi: 10.36253/web-8285

Copyright: ( 2020 E. Zhllima, D. Imami, N. Bytyqi, M. Canavari, E. Merkaj, C. Chan. This is an open access, peerreviewed article published by Firenze University Press (http://www.fupress. com/wep) and distributed under the terms of the Creative Commons Attribution License, which permits unrestricted use, distribution, and reproduction in any medium, provided the original author and source are credited.

Data Availability Statement: All relevant data are within the paper and its Supporting Information files.

Competing Interests: The Author(s) declare(s) no conflict of interest.
Original Research Article

\section{Emerging Consumer Preference for Wine Attributes in a European Transition Country - the Case of Kosovo}

\author{
Edvin Zhllima ${ }^{1}$, Drini Imami ${ }^{1, *}$, Njazi Bytyqi ${ }^{2}$, Maurizio Canavari ${ }^{3}$, \\ Elvina Merkaj ${ }^{4}$, Catherine Chan ${ }^{5}$ \\ ${ }^{1}$ Agricultural University of Tirana and CERGE EI, Albania. ${ }^{\star}$ Corresponding author \\ ${ }^{2}$ University of Pristina, Kosovo \\ ${ }^{3}$ University of Bologna, Italy \\ ${ }^{4}$ Università Politecnica delle Marche, Italy \\ ${ }^{5}$ University of Hawai ' $i$ at Manoa, USA \\ E-mail: ezhllima@ubt.edu.al, drinimami@yahoo.com,njazi.bytyqi@uni-pr.edu, maur- \\ izio.canavari@unibo.it, elvinamerkaj@yahoo.it, chanhalb@hawaii.edu
}

\begin{abstract}
This study analyzes consumer preferences for wine in Prishtina, Kosovo - a transition country in the Balkans, which is making efforts to withstand to the competition pressure from the traditional neighboring wine producing countries. With the changes in life style and consumer behavior, and incomes rising rapidly since the last conflict, it is imperative to survey the changing demand for producers to compete in the domestic markets. Conjoint Choice Experiments were used to evaluate wine consumer preferences based on wine type (white vs. red), origin (domestic vs. imported), taste (sweet vs. dry) and price. Four distinct classes of consumers were identified. The top two important attributes in the choice of wine are the type and origin but preferences vary across groups - type of wine and origin appear far more important when compared to price, especially for the richest identified segment, whose consumers prefer more expensive wines.
\end{abstract}

Keywords: consumer preferences, wine, Conjoint Choice Experiment, latent class choice model, Kosovo.

\section{INTRODUCTION}

There is a vast literature on wine consumer preferences with focus on traditional wine consumption and production countries, especially EU. Previous research about matured market countries such as Spain, Australia and Chile identifies various wine attributes preferred by consumers. These are both of intrinsic and extrinsic nature, such as price, wine aging, and grape variety (Barreiro-Hurlé et al., 2008; Lockshin et al., 2006; Mtimet and Albisu, 2006; Mueller and Szolnoki, 2010; Palma et al., 2013; Sánchez and Gil, 1998), packaging and label (Loureiro, 2003; Mueller and Szolnoki, 2010), taste (Jarvis et al., 2007), certification of origin (Mtimet and Albisu, 2006; 
Scarpa et al., 2009) and also environmental or organic label equipment (Remaud et al., 2008;Scarpa et al., 2009).

There are fewer consumer studies on developing markets or transition economies, such as Western Balkans countries, compared to the first group. Some of the studies are focused on basic attributes such as origin, type and aroma (Zhllima et al., 2012), alcoholic level (Palma et al., 2013), color (Mehta and Bhanja, 2018) and in few cases on region of origin (Jantzi and McSweeney, 2019). The socio-demographic factors such as age, gender and income have been explored vis a vis with the product attributes (Gjonbalaj et al., 2009; Zhllima et al., 2012) reflecting the benefit of collected evidences for helping wine producer to follow market segmentation based strategies.

Contribution to the existing literature is especially important for small neighboring countries of EU, which face strong competition from the single market. The objective of this study is to analyze consumer preferences for wine in Kosovo, which is a small country aspiring to join EU. Kosovo is a typical case of a country lacking competitive advantages for exporting large quantities of wine to EU (at least at medium term). However, export to niche markets, such as the Albanian Diaspora and gradual import substitution, is a potential considering the government efforts and the production trends in the post-conflict decade. Overall, the local market is and will remain crucial for the local industry as increasing competition in the export market prevails.

The study provides recommendations for the sector's stakeholders, with focus on wine market operators relying on consumer segmentation. Last but not least, since wine is an important agrifood sector in Kosovo (as shown in the following section) the study offers empirical evidence for policy makers to orient their policies to national/local food and agricultural systems, designing a concept for consumer-driven agriculture that is innovative and responsive to consumer expectations. In order to contribute to the existing literature, the study estimates the willingness to pay for domestic over imported wine. This is of relevance for the local industry which is struggling to keep its presence in the export market, while grow its share in the small but growing local market too.

The study is based on a structured survey that took place in Kosovo's capital city, Prishtine, in year 2016. Prishtine is the largest urban community in the country, with highest concentration of income and purchasing power, therefore a driving market for quality products such as wine.

The outline of the paper is structured as follows: in the following sections of the paper is provided an overview of the vineyard and wine sector in Kosovo. The third section describes the methodology followed by a separate section of results. The final section presents the conclusions of the study.

\section{BACKGROUND - VITICULTURE AND WINE MAKING IN KOSOVO}

Kosovo is situated in the Western Balkans, with a population of 1.8 million, dominated by ethnic Albanians, and it shares similarities with Albania (ethnic, cultural, language, etc.). Almost half of the population lives in rural areas. Kosovo belonged to a centrally planned economy under Yugoslavia until late 1980s, while it underwent a notorious conflict and emerged as an independent country in the following decade. The conflict resulted in human losses as well as devastated economy - the production capacities were damaged, including agriculture and specifically vineyards. Despite economic growth since independence, Kosovo remains one of the poorest European countries. Because of the troubled past, Kosovo has been facing many challenges such as weak institutional framework, which have affected also the agri-food markets and value chain organization (FAO, 2016).

Agrifood sector is considered key for economic development in Kosovo - most people live in rural areas and are engaged in the agriculture sector. Agriculture importance in Kosovo's economy remains high- its contribution to the annual GVA is $11.4 \%$ (Volk et al., 2019). The sector still suffers of many structural, organizational and capacity problems. Difficulties to recover capital and governance conditions during the post-conflict period have negatively influenced the sector, in particular the agro-processing node (including wine processing, which is the focus of this paper).

Wine production and vineyards growing is one of the most important agri-food sectors in Kosovo in terms of production and international trade, since wine is one of the main exported agri-food products. Suitable agroecological conditions combined with tradition of wine making have been key factors for the growth of wine production in the past. After achieving a production peak in the 1980s, namely 100 million liters of wine per year with strong export orientation, the sector faced a remarkable setback in the following decade. During the late 1990s conflict many vineyards were destroyed and production of grape and wine were reduced drastically. After the conflict, there was growing attention by private business, government and donors for the agriculture sector in general, and vineyard and wine specifically, which resulted in growth and renewed investments in the sec- 
tor. The government has been supporting the sector by using coupled support (Volk et al., 2019). Vine growing and wine making continues to provide a significant contribution to the Kosovo economy (Bytyqi, 2015).

In Kosovo there are cultivated more than 40 types of grapes. The total area of vineyards in 2017 was 3,199 ha, which compared with 2016 marked an increase of 3\% (KAS, 2015). Out of the total area of vineyards in 2017, $25 \%$ of the surface was planted with table grapes, while $75 \%$ with wine grapes, of which 1,583 ha is destined for red wine, which is also the dominant wine produced in Kosovo. From the cultivated area with red wine production varieties, leads the Vranac variety with 477 ha cultivated, followed by the Prokupe variety with 368 ha, Game variety with 254 ha and Black Burgundy with157 ha. Whereas grape varieties for white wine production constitute the cultivated area of 816 ha. The majority is cultivated with the Smederevka variety with a surface area of 369 ha, followed by Italian Rizling with a surface area of 220 ha, and Shardone variety with a surface area of 91 ha, while the rest of the area of 136 ha is planted with varieties such as: R. Rhaine, Zhuplanka, Rrakacitel, Semion, White Burgundy, Zhillavka, Melnik and the white of Kladova (MAFRD, 2018).

The production of wine consisted of 3.3 million litters red wine and 2 million liters white wine in 2017. The company "Stone Castle Vineyards \& Winery" leads with the highest wine production in the amount of 16,061 hl. Also this year after "Stone Castle", the second company is the "Sunny Hills" with a total of 13,568 hl, followed by "Haxhijaha" company with 8,767 hl (ibid).

Historically, Kosovo's wine industry has had a strong export orientation. Its average wine consumption is about 1 liter per capita per year according to the official estimates, which is very low compared to neighboring Balkan Countries such as Albania (ca. 6 liters per capita per year), Serbia and Macedonia (ca. 20 liters per capita per year), and much lower than the average Southern and Western European consumption (ca. 30 liters per capita per year) (FAO, 2016). One reason behind the low consumption of wine and alcohol in general is religion - the largest religious community in Kosovo is Muslims. Although many Muslims are secular (and do also drink alcohol), on the other hand, many are practicing, implying alcohol abstaining. Another reason for the low level of wine consumption is low income. Raki (so far, the main alcoholic drink consumed in Kosovo which is a brandy like Grapa, which is mostly locally produced and can be found at relatively low prices) is widely used as a less expensive substitute, often produced by households for self-consumption. With the increase of income, consumption of wine is expected to increase. The domestic wine industry, which exports a large share of its production, is keen to increase its presence or share of the production in the domestic market (aiming at substituting imports, which are strongly present especially in the upper end market segments), as part of market diversification and risk reduction strategy (FAO, 2016). However, that requires better understanding of Kosovo consumer preferences for wine, which is also the focus of this paper.

As a country in transition, a crucial problem is the lack of a proper link between the local vineyard production and processing practices and the needs and expectations of wine consumers in the domestic market. This is particularly important, given that income and lifestyles are changing fast in the context of economic growth- such changes may affect the demand for wine. Therefore, it is important to explore the consumer preferences, especially among urban consumers which are the main purchasing segment for the domestic wine in Kosovo.

\section{METHODS AND DATA}

\subsection{Overview of the approach and selection of product attributes}

While in the introduction we discussed previous studies findings on consumer preferences for various wine attributes, in this sub-section we focus on methods used by previous studies. The methods for exploring consumer preferences are typically based on panel data or large datasets of sales (as on Cortez et al., 2009) or by surveying the stated consumer preferences. The first approach provides powerful evidence of what consumers actually purchase but it is criticized for not allowing exploration of new attributes or combinations of attributes that can be realized through stated preferences (Goodman et al., 2005). One of the most commonly used methods for stated preferences in exploring consumer preferences are Choice Experiments (Barreiro-Hurlé et al., 2008; Jantzi and McSweeney, 2019; Mehta and Bhanja, 2018; Mtimet and Albisu, 2006; Rodríguez-Donate et al., 2019; Sánchez and Gil, 1998; Zhllima et al., 2012). Other authors used means-end chain approach (Barrena and Sanchez, 2009) and scale method (Joveret al., 2004; Barreiro-Hurlé et al., 2008; Bernabéu et al., 2012). In this study, a Choice Based Conjoint analysis (CBC) is used to estimate how levels of different attributes combined affect overall preference of consumers for wine in Kosovo. CBC permits respondents to choose between full product combinations against each other instead of rating or ranking the product based on the attributes. 
The CBC derives from the theoretical basis established by Lancaster (1966) according to which the utility of a product is based on the bundle of attributes it has (quoted at Mtimet et al., 2008). It was earlier developed by Louviere and Woodworth (1983) and was originally used in the market research and transport literature (Hensher, 1994). It has also been used widely as a method for conducting surveys on consumer preferences for environmental amenities. The utility of any good is derived from the characteristics of the good rather than the good itself (Lancaster, 1966). The analysis is based on the idea that a good can be described by its attributes or characteristics and by the levels of those attributes.

Majority of the authors following these experiments used face to face interviews while some have used webbased experiments (see Palma et al., 2013). Experiments can also include sensory tests (see Jarvis et al., 2007). In this study, choice experiments have been applied face to face (see Bytyqi et al., 2015), similar to Zhllima et al. (2012) in Albania. In order to implement this approach, there are five stages for developing a CBC, namely selection of attributes, assignment of their level, design of choice sets, collecting data and conducting analysis (Cattin and Wittink, 1982; Green and Wind, 1975). The stages for this study are shown in Table 1 below.

Attributes in a conjoint design are fundamental characteristics of the product that describe and differentiate it from others in the market. We chose attributes and their level based on literature review, market observations and expert consultations. To validate the attributes and the levels chosen in this early stage, a focus group was organized with different categories of wine consumers in Kosovo. The attributes chosen for

Table 1. Stages of a Conjoint Choice Experiment and Analysis.

\begin{tabular}{ll}
\hline Stage & \multicolumn{1}{c}{ Description } \\
\hline 1. Selection of attributes & $\begin{array}{l}\text { Attributes and attribute levels were } \\
\text { selected based on a focus group } \\
\text { with stakeholders and an extensive } \\
\text { literature review }\end{array}$ \\
$\begin{array}{ll}\text { 2. Assignment of attribute } \\
\text { levels }\end{array}$ & $\begin{array}{l}\text { 3. Construction of choice sets } \\
\text { The SSI Web program using the } \\
\text { orthogonal array was used to create } \\
\text { the profiles in the survey } \\
\text { Survey was conducted via face-to- } \\
\text { face interviews in different week days } \\
\text { Data is analyzed with latent class } \\
\text { approach }\end{array}$ \\
5. Data collection &
\end{tabular}

Source: Chan-Halbrendt et al. (2010). this study's objective are price, type, origin and taste. Attributes in this paper are chosen by considering the importance, relevance and parsimony criteria (Simmons and Esser, 2001). They are important in describing the wine market in Kosovo, to differentiate various types of wine and take also into account the complexity of the conjoint design. To generate an optimal conjoint design, the levels of the attribute were chosen to be independent from one another, clearly defined along one dimension to avoid misinterpretation of the consumers, realistic as they represent the wine market in Kosovo and balanced as the number of levels does not vary too much between attributes. The type and level of attributes selected to analyze wine preferences in Kosovo are represented in Table 2.

Price attribute is typically present in wine conjoint studies (Joveret al., 2004; Lockshin et al., 2006; Mtimet and Albisu, 2006; Sánchez and Gil, 1998; Zhllima et al., 2012). Some studies use equally distant price levels while others identify price segments which are more representative to certain product groups. In our study we have defined the price levels (from 2.2 Euro to 7.5 Euro) based on the focus group with consumers and observations in the market.

Another important attribute is type. The industry of wine has been prone to produce more red rather than white wine, due to technology constraints, while the focus group with consumers has identified type as a key factor in their choices. Given the low diversity of wines in the Kosovo market and based on the literature for developing country markets (see Barreiro-Hurlé et al., 2008; Mehta and Bhanja, 2018) two main categories for wine were chosen to be explored through the experiment, namely red and white.

Discussions in the focus group with consumers identified also taste as a very important variable. Therefore, similar to Joveret al. (2004), Jarvis et al. (2007), and Zhllima et al. (2012) it was decided to select two levels of taste, namely sweet and dry wines. Participants in the

Table 2. Wine Attributes and Levels chosen for the CBC experiments in Kosovo.

\begin{tabular}{ccccc}
\hline & \multicolumn{4}{c}{ Attributes } \\
\cline { 2 - 5 } & Price (liter) & Type & Origin & Taste \\
\hline Level of attributes & $7.50 €$ & White & Domestic & Sweet \\
& $5.50 €$ & Red & Imported & $\begin{array}{c}\text { Not sweet } \\
(\text { dry })\end{array}$ \\
& $4.00 €$ & & & \\
$2.20 €$ & & & \\
\hline
\end{tabular}

Source: Authors. 
focus group expressed difficulties to express and explain other taste attributes.

Origin is another important attribute. Some studies (Barreiro-Hurlé et al., 2008; Lockshin et al., 2006; Zhllima et al., 2012) are more interested to understand the consumer preferences toward domestic product while other studies, especially in recent years (Jantzi and McSweeney, 2019; Mueller and Szolnoki, 2010), are focusing more on the region of origin and other intrinsic signals linked with it. Considering the fact that wine production in Kosovo is focused on a homogenous and relatively narrow area, authors chose to follow the example of the earlier studies. Moreover, study findings in this direction are more relevant for the local industry and the policymaking institutions, strongly focused on import substitution.

\subsection{Experimental design and construction of choice set}

Sowtooth Software SSI Web was used to design the experiment, prepare and analyze the data. To ensure an efficient design of the survey seven versions of the questionnaire were generated. For each version, attributes and levels of the product were combined into 12 hypothetic market scenarios (choice task) each composed of four subsets of product alternatives (concept). Each respondent was shown one version of the questionnaire and was asked to choose between four alternatives of the product with the specific attributes proposed in a hypothetic market scenario for all the 12 scenarios of the questionnaire. Table 3 represents an example of hypothetic market scenarios.

The Complete Enumeration method ${ }^{1}$ was used to combine the various attributes and levels to develop potential products choices for the respondents. This approach ensures orthogonal concepts within each version of the questionnaire and balances the two-way frequency of level combinations between attributes (Green and Srinivasan 1978). Moreover this method generates combinations with the minimum overlap of attributes making the alternatives in a choice task as different as possible. The quick test ${ }^{2}$ was used to test the efficiency and integrity of the $\mathrm{CBC}$ design. It provides a good approximation of the relative efficiency of the $\mathrm{CBC}$ design with respect to each attribute level.

\footnotetext{
${ }^{1}$ The Sowtooth Software was used for the analysis in this work

${ }^{2}$ The quick test, for each attribute and level, makes an approximation of the relative standard error of each main effect under aggregate analysis and assuming that each version is seen just once across the total observations. The quick test uses ordinary least squares efficiency. It provides a good approximation of the relative efficiency of the CBC design with respect to each attribute level. (https://www.sawtoothsoftware.com/help/ issues/ssiweb/online_help/hid_web_cbc_designs_6.htm)
}

Table 3. Example of a product task with four product concepts in the questionnaire.

If these were your only options, which wine would you choose (to buy)?

\begin{tabular}{cccc}
\hline $7.50 €$ & $5.50 €$ & $4.00 €$ & $2.20 €$ \\
Red & Red & White & White \\
Imported & Imported & Local & Imported \\
Not sweet(dry) & Sweet & Not sweet(dry) & Sweet \\
$\square$ & $\square$ & $\square$ & $\square$ \\
\hline
\end{tabular}

Source: Authors.

\subsection{Data collection}

Green and Srinivasan (1978) suggest a minimum sample of 100 respondents for conjoint analysis types of studies - in our case there were 215 valid questionnaires. Interviews were administered during 2014 by trained graduate students. The interviews were carried out at various sites (e.g. shopping malls, open markets, streets) in Prishtina - people were approached randomly and after completing each face-to-face interview, interviewers would approach the next closest person who walked by.

Table 4 shows the gender and age structure of survey respondents compared to Prishtina population statistics. While gender wise, the sample structure is similar to that of the population, elderly people are slightly under represented in the sample when compared to the population.

\subsection{Data analysis method: Latent class analysis}

Latent class method is used to analyze the data of our experiment. This approach is used extensively in

Table 4. Socio- demographic comparison of survey respondents with Prishtina population.

\begin{tabular}{llll}
\hline & & $\begin{array}{c}\text { Survey Respondents } \\
(\%)\end{array}$ & $\begin{array}{c}\text { Prishtina Population } \\
(\%)\end{array}$ \\
\hline Gender & Female & 52.3 & 50.0 \\
& Male & 47.7 & 50.0 \\
Age $^{*}$ & $18-35$ & 40.7 & 43.5 \\
& $36-50$ & 43.1 & 30.6 \\
& 51 and up & 16.2 & 25.8 \\
\hline
\end{tabular}

Source: Own calculations for the survey respondents and Kosovo Statistical agency for the Prishtina population.

* Note: the survey targeted adult consumers (consumers below 18 years were not considered for interview). Thus, to make the structure comparable between the sample and the population, only the structure of adult population is shown. 
recent years to group consumers based on their preferences. The model segments respondents into finite groups with homogenous preferences expressed in the experiment, even though the population is presumed to have heterogeneous preferences. This way the preferences are relatively homogenous within segments but differ from one segment to another.

Latent class model allows the estimation of part worth utility for each homogeneous group based on the choices of the respondent in the conjoint experiment. According to McFadden (1974) the probability that individual $\mathrm{n}$ chooses profile $i$ in the CBC experiment can be described as follows:

$P_{i i}=\frac{\exp \left(\mathrm{h} X_{\dot{i}}\right)}{\sum_{h=1}^{I} \exp \left(\mathrm{h} X_{h}\right)}$

where $\mathrm{P}_{n i}$ is the probability of respondent $n$ choosing profile $i, \eta$ denotes a scale parameter, and $X_{n i}$ is the deterministic component that is assumed to be a linear function of explanatory variables.

LCA approach assumes that the sample of individuals is drawn from a population that consists of a finite number of latent classes, say $m$, and that each element in the sample can be regarded as a draw from one of these $\mathrm{m}$ latent groups.

Equation 1 can be rewritten for LCA to give the following equation:

$P_{n i \mid m}=\frac{\exp \left(\eta_{m} \beta_{m} Z_{n i}\right)}{\sum_{h=1}^{I} \exp \left(\eta_{m} \beta_{m} Z_{n k}\right)}$

where $\mathrm{P}_{\mathrm{ni} \mid \mathrm{m}}$ means the probability of individual $n$ who chooses profile $i$ belongs to class $m, \eta_{m}$ means the classspecific scale parameter and $\beta_{\mathrm{m}}$ is the class-specific estimated utility parameter, $Z_{n i}$ are explanatory variables of $X_{n i}$.

This approach assigns to any respondent a probability of membership in each segment that sum to unity, differently from a cluster analysis where respondents are assigned to each class in a discrete manner. The sum of the probabilities of membership across respondents for each group defines the total weight (class size) of that segment.

In LCA respondents are segmented based on their choices in the CCE experiment. In our study we take into account only the product of wine as parameters to group the preferences of consumers. Due to software limitation the respondents were segmented based only on their choices of the wine attributes.
Table 5. Summary statistics of latent class analysis.

\begin{tabular}{lcccc}
\hline Groups & Cert & CAIC & Chi Sq & Rel Chi Sq \\
\hline 2 & 29.3 & 5155.8 & 2107.7 & 234.2 \\
3 & 35.4 & 4768.2 & 2539.6 & 181.4 \\
4 & 39.2 & 4537.9 & 2814.2 & 148.1 \\
5 & 42.4 & 4352.9 & 3043.5 & 126.8 \\
6 & 45.2 & 4196.4 & 3244.3 & 111.9 \\
\hline
\end{tabular}

Source: Authors calculations based on field survey.

The estimation of the model was carried out using maximum likelihood method. Estimated parameters vary for different classes. In maximum likelihood methodology the starting point is important since the model can estimate local maxima. To avoid local maxima we conducted 100 replications for each segment starting from different points. The results shown are the best fit for a 4 class segmentation considering the relative change of Consistent Akaike Info Criterion (Table 5).

\section{RESULTS}

Results of the CBC experiments are shown in Tables 6 and Table 7. Table 6 shows sample size and the importance of the attributes for each of the identified classes, whereas Table 7 shows the estimated parameters and the level of significance. All attribute levels coefficients, except for taste in the case of class 1 , are statistically significant.

The wine consumers in Kosovo are grouped in 4 (four) distinct classes that differ in their preferences for the attributes of wine. Almost one fourth of the respondents are in Class 1 (27\%) who give over $50 \%$ of the importance to the type of wine (approximately 55\%), followed by the origin of the wine (26\%). These respondents prefer white wine from Kosovo (ethno-white wine

Table 6. Class sizes and importance of attributes.

\begin{tabular}{lcccc}
\hline Description & Class 1 & Class 2 & Class 3 & Class 4 \\
\hline Class Size & $26.60 \%$ & $27.00 \%$ & $36.10 \%$ & $10.30 \%$ \\
\hline Attribute & \multicolumn{4}{c}{ Importance of attributes (\%) } \\
\hline Price & $17.09 \%$ & $11.52 \%$ & $3.36 \%$ & $6.46 \%$ \\
Type & $54.64 \%$ & $67.08 \%$ & $45.34 \%$ & $34.29 \%$ \\
Origin & $25.66 \%$ & $13.01 \%$ & $26.41 \%$ & $28.63 \%$ \\
Taste & $2.61 \%$ & $8.39 \%$ & $24.89 \%$ & $30.62 \%$ \\
Total & $100 \%$ & $100 \%$ & $100 \%$ & $100 \%$ \\
\hline
\end{tabular}

Source: Authors calculations based on field survey. 
Table 7. Latent class model parameter estimates.

\begin{tabular}{|c|c|c|c|c|c|c|c|c|}
\hline \multirow{2}{*}{$\begin{array}{l}\text { Indicator } \\
\text { Attribute }\end{array}$} & \multicolumn{2}{|c|}{ Class 1} & \multicolumn{2}{|c|}{ Class 2} & \multicolumn{2}{|c|}{ Class 3} & \multicolumn{2}{|c|}{ Class 4} \\
\hline & Utility & T-ratio & Utility & T-ratio & Utility & T-ratio & Utility & T-ratio \\
\hline Price & -0.194 & -4.803 & -0.191 & -4.458 & -0.094 & -2.094 & 0.199 & 2.363 \\
\hline \multicolumn{9}{|l|}{ Type } \\
\hline White & 0.932 & 16.627 & -1.669 & -16.779 & -1.904 & -21.728 & 1.583 & 10.618 \\
\hline Red & -0.932 & -16.627 & 1.669 & 16.779 & 1.904 & 21.728 & -1.583 & -10.618 \\
\hline \multicolumn{9}{|l|}{ Origin } \\
\hline Domestic & 0.438 & 9.489 & -0.324 & -6.554 & 1.109 & 16.295 & -1.320 & -9.309 \\
\hline Import & -0.438 & -9.489 & 0.324 & 6.554 & -1.109 & -16.295 & 1.320 & 9.309 \\
\hline \multicolumn{9}{|l|}{ Taste } \\
\hline Sweet & -0.04 & -1.03 & -0.21 & -4.63 & 1.05 & 16.14 & 1.41 & 9.86 \\
\hline Not sweet & 0.04 & 1.03 & 0.21 & 4.63 & -1.05 & -16.14 & -1.41 & -9.86 \\
\hline
\end{tabular}

Source: Authors calculations based on field survey.

Table 8. Income levels by identified consumer class.

\begin{tabular}{|c|c|c|c|c|c|c|}
\hline Income range & Class & Class 1 & Class 2 & Class 3 & Class 4 & Total \\
\hline \multirow[t]{2}{*}{$0-300 €$} & Count & 8 & 12 & 23 & 1 & 44 \\
\hline & Percentage & $13.8 \%$ & $20.7 \%$ & $29.9 \%$ & $4.5 \%$ & $20.5 \%$ \\
\hline \multirow[t]{2}{*}{$301-600 €$} & Count & 33 & 29 & 31 & 4 & 97 \\
\hline & Percentage & $56.9 \%$ & $50.0 \%$ & $40.3 \%$ & $18.2 \%$ & $45.1 \%$ \\
\hline \multirow[t]{2}{*}{$601-900 €$} & Count & 11 & 12 & 15 & $8^{\star}$ & 46 \\
\hline & Percentage & $19.0 \%$ & $20.7 \%$ & $19.5 \%$ & $36.4 \%^{*}$ & $21.4 \%$ \\
\hline \multirow[t]{2}{*}{ Above $900 €$} & Count & 6 & 5 & 8 & $9^{*}$ & 28 \\
\hline & Percentage & $10.3 \%$ & $8.6 \%$ & $10.4 \%$ & $40.9 \%^{*}$ & $13.0 \%$ \\
\hline \multirow[t]{2}{*}{ Total } & Count & 58 & 58 & 77 & 22 & 215 \\
\hline & Percentage & $100 \%$ & $100 \%$ & $100 \%$ & $100 \%$ & $100 \%$ \\
\hline
\end{tabular}

${ }^{\star}$ Chi square $=0.000$.

Source: Authors calculations based on field survey.

lovers). Class 2 (27\%) predominantly prefer red wine with $67 \%$ importance placed on this attribute. This group also prefers competitively priced imported wine (cheap foreign red wine lovers). Class 3 (36\%) placed the most important attribute on the type of wine (red) followed equally by the attributes of domestic and sweet tasting wine (ethno-red and sweet wine lovers).

The last group with the smallest share of respondents $(10 \%)$ placed almost equal importance to the type (white) and origin (imported) sweet wine (richwhite sweet foreign wine lovers). This class is the only segment of consumers that has a preference for high prices wine, implying that high price is perceived as a signal of quality guarantee.

Several tests were run to assess possible socio-demographic variable differences across groups - not statistically significant differences were found for education, gender and age. The only variable which appears to differ significantly across groups is income - class 4 has a stronger presence of higher income households. Indeed, class 4 consumers, as shown above, being also the wealthiest class, are first and foremost interested in quality, reflected by their preferences for higher price wines.

Regarding willingness to pay, class 1 has a strong preference for domestic wine - they would consider imported wine only if it were 4.5 EUR cheaper. On the contrary, Class 2 consumers prefer imported wine - they would switch to local wine, if it were 3.4 EUR cheaper. Class 4 has a positive price coefficient - thereby calculation of WTP is meaningless. For class 3, which is also the largest class, price is the least important factor; thereby they would not switch from domestic to import or from red to white wine, even for significant price difference. 


\section{CONCLUDING REMARKS}

The paper explored consumer preferences for wine in Prishtina, Kosovo - a transition country in the Balkans, which has been overcoming major transformations in the vineyard sector and remains under continuous market competition from traditional wine consumer countries in both Western Balkans and EU market. Considering these conditions, it is imperative to observe the changing demand for producers to compete in the domestic markets. CCE were used to evaluate wine consumer preferences. Following a latent class choice model there are identified four distinct classes of consumers. More than $1 / 4$ of the market are classified as ethno-white wine lovers. Together with Class 3, the ethno-red and sweet wine lovers, they constitute more than half of the existing market. These two classes are the main current segment for which local producers should carefully drive a promotion using ethnic oriented promotion, using strong signals through label information, design and story-telling which recall the countries tradition for both local and diaspora consumers.

Local producers should keep considering various instruments for targeting the remaining classes, namely the cheap foreign red wine lovers as well as white sweet foreign wine lovers. These classes are very different, and cannot be targeted using the same price policy since the first is cost oriented while the second is the only segment of consumers that has a preference for high prices wine, implying that high price is perceived as a signal of quality guarantee, similar to Jarvis et al. (2007) and Zhllima et al. (2012). The producers in this case should create a divided production basket. On one hand they can create sub-brands for which they have to invest on better technologies and know-how for improving wine quality, and compensate increased costs with higher prices. This is an important step considering the majority of consumers (more than 60\%) can accept price increase, since they are expressing positive willingness to pay for domestic wine or are not price sensitive. For instance, classes which are not price sensitive and oriented to domestic wine, such as the case of ethno-white wine and ethno-red and sweet wine lovers found respectively in Class 1 and Class 3. On the other hand, a separate share of the product portfolio should be focused on price sensitive consumers, such as the case of cheap foreign red wine lovers. They expressed a willingness to convert their preferences toward domestic wine in case of price reduction. This class, providing more than $1 / 4$ of the market, might be the short term goal of the wine processing industry in Kosovo.

The most important attribute in the choice of wine in Kosovo is the type. Two consumer classes, includ- ing the biggest one, prefer red wine. This is very similar to Albania where majority of the consumers prefer red wine (see Zhllima et al., 2012). The consumption of red wine is also related to food life style and previous experiences on local white wines. Thus, when considering the vineyards investments, red wine grape cultivars should be considered in order to match the general preferences related to type.

Similar to Jarvis et al. (2007) the taste of the wine is important too. This is an evidence for reaching the consumer interests by adding information on labels on regards to wine taste characteristics, especially for the sweet oriented consumers such as those found in class 3 and class 4 . Moreover, producers should make efforts for strictly controlling the postharvest and processing protocols in order to control the alcohol content, by emphasizing the flavor and sweetness of the wine.

Considering these results, wine processors can strategically opt for competitive lower price wines in larger urban markets. A diversification strategy may be created where a small portion of the production of high quality wine may compete for a space on upper shelves where also imported wines are shelved. This strategy would target Class 4 consumers who prefer white, imported wines. Particular attention should be given to ethnic oriented consumers by focusing efforts on certification, promotion of regional origin differences, labelling and packaging which are important in other studies. To produce quality white wine, additional investments are required to improve the production technology in addition to a better vertical coordination with raw material suppliers. Consumer education and tourism can be explored to increase wine consumption and strengthen the image of the local producers. In this way, product should be part of culinary offers and be strengthened with description of natural amenities of the production areas.

The study is based on urban consumer preferences and as such it has limitations in understanding wine production potentials - future research should explore also rural consumer preferences. Moreover, future research can rely on sensory testing method which would be an added value for understanding consumer preferences related to taste. Other attributes are necessary to be explored in the future. For instance, recent decade studies (see Lockshin et al., 2006; Mueller and Szolnoki, 2010; Remaud et al., 2008) have explored the area of origin as an attribute to attract selected market segments. In addition, choice experiments have been developed in order to understand consumer WTP for missing attributes such as Protected Designation of Origin (PDO) and Protected Geographical Indication (PGI). 
Studies in this sphere are crucial for casting light to new product strategies for local producers in relevance with local and native varieties. Moreover, research is utilized to evaluate the feasibility of adoption of GI certification schemes for wine producers, which is a viable instrument for reducing the pressure of international wine market, especially in the case of an EU neighboring country.

\section{REFERENCES}

Barreiro-Hurlé, J., Colombo, S.\&Cantos-Villar, E., 2008. Is there a market for functional wines? Consumer preferences and willingness to pay for resveratrolenriched red wine. Food Quality and Preference 19 (4), 360-371.

Barrena, R.,\&Sanchez, M., 2009. Connecting product attributes with emotional benefits: analysis of a Mediterranean product across consumer age segments. British Food Journal 111(2), 120-137.

Bernabéu, R., Díaz, M., Olivas, R. \& Olmeda, M., 2012. Consumer preferences for wine applying best-worst scaling: a Spanish case study. British Food Journal, 114(9), 1228-1250.

Bytyqi, Nj., 2015. Analysis of the consumer preferences of some important agrifood products in Kosovo applying Conjoint Choice Experiment. PhD thesis, Defended at Agricultural University of Tirana in 2015.

Bytyqi, Nj., Skreli, E., Vercuni, A., Imami, D.\&Zhllima, E., 2015. Analyzing Consumers' Preferences for Apples in Prishtina.BOKU Journal, No. 66, 1-2.

Cattin, P. \&D.R. Wittink. 1982. Commercial Use of Conjoint Analysis. Journal of Marketing. 46:44-53.

Chan-Halbrendt, C., Zhllima, E., Sisior, G., Imami, D. \& Leonetti, L., 2010. Consumer preferences for olive oil in Tirana, Albania. International Food and Agribusiness Management Review, 13(3).

Cortez, P., Cerdeira, A., Almeida, F., Matos, T.\&Reis, J., 2009. Modeling wine preferences by data mining from physicochemical properties. Decision Support Systems, 47(4), 547-553.

FAO2016.Value Chain Study, Technical report prepared in the context of FAO Project "Capacity development of MAFRD economic analysis unit on agricultural policy impact assessment (in Kosovo)", TCP/ KOS/3501.

Gjonbalaj, M., Miftara, I., Pllana, M., Fetahu, S., Bytyqi, H., Gjergjizi, H., \& Dragusha, B., 2009.Analyses of Consumer Behavior and Wine Market in Kosovo. Agriculture Conspectus Scientificus (ACS) 74(4), 333-338.
Goodman, S., Lockshin, L., \& Cohen, E., 2005.Best-worst scaling: a simple method to determine drinks and wine style preferences, International Wine Marketing Symposium, Sonoma 2005.

Green, P.E. \&Wind. Y., 1975. New Ways to Measure Consumers' Judgments. Harvard Business Review, 89-108.

Green, P. E., \&Srinivasan, V., 1978. Conjoint Analysis in Consumer Research: Issues and Outlook. The Journal of Consumer Research 5, 103-123.

Hensher, D.A. 1994. Stated preference analysis of travel choices: the state of practice. Transportation, 21: 107133.

Jantzi, H. A., \&McSweeney, M. B., 2019. An overview of wine consumers in Nova Scotia, Canada: A conjoint analysis study. Journal of Wine Research, 30(1), 48-61.

Jarvis, W., Rungie, C., \& Lockshin, L., 2007. Revealed preference analysis of red wine attributes using polarization. International Journal of Wine Business Research 19(2), 127-138.

Jover, A. J. V., Montes, F. J. L., \& Fuentes, M. D. M. F., 2004. Measuring perceptions of quality in food products: the case of red wine. Food Quality and Preference 15(5), 453-469.

KAS 2015.Agricultural Census in the Republic of Kosovo 2014. Available at: http://ask.rks-gov.net/media/1375/ final-results.pdf

Lancaster, K. J., 1966. New approach to consumer theory. Journal of Political Economy, 74:132- 157.

Lockshin, L., Jarvis, W., d'Hauteville, F., \&Perrouty, J. P., 2006.Using simulations from discrete choice experiments to measure consumer sensitivity to brand, region, price, and awards in wine choice. Food quality and preference 17(3), 166-178.

Loureiro, M. L., 2003. Rethinking new wines: implications of local and environmentally friendly labels. Food Policy 28(5), 547-560.

Louviere, J.J. \&G.G. Woodworth. 1983. Design and analysis of simulated consumer choice or allocation experiments: An approach based on aggregated data. Journal of Marketing Research, 20: 350-367

McFadden, D. S. 1974. Conditional logit analysis of qualitative choice behaviour. Frontiers in econometrics. New York: Academic Press.

Mehta, R., \&Bhanja, N. 2018. Consumer preferences for wine attributes in an emerging market. International journal of retail \& distribution management, 46(1), 34- 48.

Ministry of Agriculture, Forestry and Rural Development-MAFRD 2018. "Green Report, 2018”, Pristina.

Mtimet, N., \&Albisu, L. M., 2006. Spanish wine consumer behavior: A choice experiment approach. Agribusiness 22(3), 343-362. 
Mtimet, N., Kashiwagi, K., Zaibet, L., \& Masakazu, N. 2008. Exploring Japanese olive oil consumer behavior (No. 725-2016-49724).

Mueller, S. \& Szolnoki, G., 2010. The relative influence of packaging, labelling, branding and sensory attributes on liking and purchase intent: Consumers differ in their responsiveness. Food Quality and Preference 21(7), 774-783.

Palma, D. E., de Dios Ortúzar, J., Rizzi, L. I., Agosin\&E., Casaubon, G., 2013. Modeling wine consumers preferences: How different can consumers be?.In International Choice Modelling Conference.

Remaud, H., Mueller, S., Chvyl, P.\&Lockshin, L., 2008. Do Australian wine consumers value organic wine? In: Proceedings of the International Conference of the Academy of Wine Business Research. 17-19 July 2008. Siena, pp. 1-15

Rodríguez-Donate, M. C., Romero-Rodríguez, M. E., CanoFernández, V. J., \& Guirao-Pérez, G., 2019. Analysis of heterogeneity in the preferences of wine consumption. Wine Economics and Policy, 8 (1), pp. 69-80.

Sánchez, M., Gil, J. M., 1998. Consumer preferences for wine attributes in different retail stores: a conjoint approach. International journal of wine marketing $10(1), 25-38$.

Scarpa, R., Thiene, M. \& Galletto, L., 2009. Consumers WTP for wine with certified origin: preliminary results from Latent Classes based on attitudinal responses. Journal of food products marketing 15(3), 231-248.

Simmons S.\&Esser M., 2001. Developing Business Solutions from Conjoint Analysis. In: Gustafsson A., Herrmann A.\& Huber F. (eds) Conjoint Measurement. Springer, Berlin, Heidelberg

Volk, T., Rednak, M. Erjavec, E. Rac, I. Zhllima, E. Gjeci, G. Bajramović, S. Vaško, Ž. Kerolli-Mustafa, M. Gjokaj, E. Hoxha, B. Dimitrievski, D. Kotevska, A. Janeska Stamenkovska, I. Konjevic, D. Spahic, M. Bogdanov \& Stevović M. (authors), Ilic, B. Pavloska - Gjorgjieska D., Ciaian,P. (editors),2019. Agricultural policy developments and EU approximation process in the Western Balkan countries, EUR 29475 EN, Publications Office of the European Union, Luxembourg, doi:10.2760/583399, JRC114163.

Zhllima, E., Chan-Halbrendt, C., Zhang, Q., Imami, D., Long, R., Leonetti, L. \& Canavari, M., 2012.Latent class analysis of consumer preferences for wine in Tirana, Albania. Journal of International Food \& Agribusiness Marketing 24(4), 321-338. 